\title{
Snake Bite Induced Acute Renal Failure: A Study of Clinical Profile and Predictors of Poor Outcome
}

\author{
Tushar B Patil ${ }^{\mathrm{a}, \mathrm{b}}$, Yogendra V Bansod ${ }^{\mathrm{a}}$, Mangesh B Patil ${ }^{\mathrm{a}}$
}

\begin{abstract}
Background: Acute renal failure is an important cause of morbidity and mortality in snake bite patients, especially in tropical countries. This study was aimed to describe clinical profile and to identify predictors of poor outcome in snake bite induced acute renal failure.
\end{abstract}

Methods: This was a retrospective observational study, conducted in a tertiary care hospital, 57 patients of snake bite induced ARF, who required dialysis were included. Clinical history taking, physical examination and laboratory evaluation was done. All patients received standard treatment including Antisnake venom. Patients received peritoneal or hemodialysis depending on availability of resources. The Pearson Chi-Square Test was used to analyze parametric variables.

Results: Prevalence of ARF in snake bite was 20.48\%.Common clinical manifestations were local cellulitis (100\%), oliguria $(84.2 \%)$, edema $(33.3 \%)$, hematuria $(29.8 \%)$, altered sensorium $(26.3 \%)$ and bleeding manifestations $(22.8 \%)$. Common laboratory findings were albuminuria (100\%), anaemia (54.3\%); leucocytosis (61.4\%); thrombocytopenia (42.1\%); coagulopathy (36.8\%); metabolic acidosis $(31.5 \%)$.

Conclusions: Snake bite induced ARF has mortality of $15.5 \%$. The factors associated with mortality were presence of coagulopathy and uremic encephalopathy. Though this study is not designed to compare hemodialysis and peritoneal dialysis, the better outcome in hemodialysis group suggests the need to compare the two modalities of renal replacement therapy in patients with snake bite induced acute renal failure.

Manuscript accepted for publication June 12, 2012

${ }^{a}$ Department of Medicine, Government Medical College, Nagpur, Maharashtra, India

${ }^{\mathrm{b}}$ Corresponding author: Tushar B. Patil, Plot No. 9, Rashtrasant Nagar, Godhani Road, Zingabai Takli, Nagpur-440030, Maharashtra, India. Email: dr.tushar42@rediffmail.com

doi:10.4021/wjnu13w
Keywords: Snake bite; Acute renal failure; Coagulopathy; Uremic encephalopathy; Hemodialysis

\section{Introduction}

Snake bite is a common cause of morbidity and mortality worldwide, especially in tropical countries. Globally, at least 421,000 envenomings and 20,000 deaths occur each year due to snakebite. These figures may be as high as $1,841,000$ envenomings and 94,000 deaths. Based on the fact that envenoming occurs in about one in every four snakebites, between 1.2 million and 5.5 million snakebites could occur annually [1]. In many parts of Southeast Asian region, snake bite is a familiar occupational hazard of farmers, plantation workers and others, resulting in tens of thousands of deaths each year and innumerable cases of chronic physical handicap [2]. India accounts for about 30,000 deaths per year due to snake bite [3].

Of the $2500-3000$ species of snakes, only 500 are considered to be venomous [4]. There are two important groups (families) of venomous snakes in Southeast Asia -Elapidae have short permanently erect fangs. This family includes the cobras, king cobra, kraits, coral snakes and the sea snakes. Viperidae have long fangs which are normally folded up against the upper jaw but, when the snake strikes, are erected. There are two subgroups, the typical vipers (Viperinae) and the pit vipers (Crotalinae) [2]. The concept of the "Big 4" Snakes of medical Importance in India are- the Indian cobra (Naja naja), the common krait (Bungarus caeruleus), the Russell's viper (Daboia russelii) and the saw-scaled viper (Echis carinatus) [5-6].

Acute renal failure is mainly observed following bites by the viperidae group, sea snakes and the colubridae group, but the substantial number of cases result from viper bites. Tubular necrosis and cortical necrosis are the main causes of ARF [7].

The objectives of this study were to describe the clinical profile of the snake bite patients who develop acute renal failure; to identify the indications and role of dialysis in these patients and to identify the predictors of mortality in 
Table 1. Timing of Snake Bite, Site of Snake Bite and the Time Lag Between Snake Bite and Administration of First Dose of ASV

\begin{tabular}{lll}
\hline & Time of Snake Bite & No. of Patients $(\mathbf{n}=\mathbf{5 7})$ \\
\hline 1 & $6 \mathrm{am}-2 \mathrm{pm}$ & $23(40.3 \%)$ \\
2 & $2 \mathrm{pm}-10 \mathrm{pm}$ & $28(49.1 \%)$ \\
3 & $10 \mathrm{pm}-6 \mathrm{am}$ & $06(10.5 \%)$ \\
\hline & Time Lag & No. of patients $(\mathbf{n}=\mathbf{5 7})$ \\
\hline 1 & $0-12$ hrs & $16(28.07 \%)$ \\
2 & $12-24$ hrs & $13(22.8 \%)$ \\
3 & $24-48 \mathrm{hrs}$ & $11(19.2 \%)$ \\
4 & $>48$ hrs & $17(29.8 \%)$ \\
\hline & Site & No. of Patients $(\mathbf{n}=\mathbf{5 7})$ \\
\hline 1 & Right upper limb & $10(17.5 \%)$ \\
2 & Left upper limb & $4(7.01 \%)$ \\
3 & Right lower limb & $19(33.3 \%)$ \\
\hline 5 & Oeft lower limb & $24(42.1 \%)$ \\
\end{tabular}

these patients.

\section{Subjects and Methods}

We studied case records of 57 patients of snake bite, developing acute renal failure, who were admitted for renal replacement therapy, from June 2007 to December 2008. The inclusion and exclusion criteria were defined as follows.

Inclusion Criteria: 1) Definitive history of snake bite; 2) Clinical picture consistent with snake bite, as presence of fang marks or cellulitis or coagulopathy or neuroparalysis; 3) Presence of Acute Renal Failure, defined as an abrupt (within 48 hours) absolute increase in the serum creatinine concentration of $\geq 0.3 \mathrm{mg} / \mathrm{dL}$ from baseline value measured after admission to our hospital or elsewhere after snake bite, before referral to our hospital, or a percentage increase in the serum creatinine concentration of $\geq 50$ percent above baseline, or oliguria of less than $0.5 \mathrm{~mL} / \mathrm{kg}$ per hour for more than six hours Serum creatinine more than $1.5 \mathrm{mg} / \mathrm{dL}$ or oliguria (urine output less than $400 \mathrm{~mL} /$ day) [8]; 4) Presence of at least one or more indication of renal replacement therapy.

Exclusion Criteria: 1) Patients with pre-existent renal disease (Serum creatinine $>1.5 \mathrm{mg} / \mathrm{dL}$ prior to snake bite or ultrasonography of abdomen suggestive of bilateral small kidneys/loss of corticomedullary differentiation / obstructive nephropathy/other renal pathology); 2) Diagnosed cases of hypertension/diabetes mellitus; 3) Patients with malaria diagnosed on peripheral smear; 4) Exposure to nephrotoxic drugs/toxins.

Clinical history taking and complete physical examination were done in each case. Laboratory investigations included hemoglobin, total and differential leucocyte counts, platelet counts, red cell counts, bleeding and clotting time, coagulation profile including prothrombin time, activated partial thromboplastin time and international normalised ratio (INR), urine microscopy, urine albumin, kidney and liver function tests and serum Electrolytes. Radiological investigations included X-ray chest and ultrasonography of abdomen.

All patients received tetanus toxoid. As all these patients had renal failure, they were considered as having severe envenomation, and hence Anti-Snake Venom (ASV) was administered in a dose of $100 \mathrm{~mL}$ as an intravenous infusion in a drip over 30 minutes. Antibiotics and Diuretics were administered, as indicated. Blood/Blood Products transfusions were given to indicate patients. Renal replacement therapy (either Peritoneal/Haemodialysis, depending upon availability of resources), was given to all 57 patients.

Patients were classified as per outcome in the form of 
Table 2. Clinical Characteristics of Patients

\begin{tabular}{|c|c|}
\hline Symptomatology & No. of patients \\
\hline 1. Local swelling & $57(100 \%)$ \\
\hline 2. Hematuria & $17(29.8 \%)$ \\
\hline 3. Oliguria & $48(84.2 \%)$ \\
\hline 4. Edema-Edema feet/ puffiness of face/Anasarca & $19(33.3 \%)$ \\
\hline 5. Breathlessness & $14(24.5 \%)$ \\
\hline 6. Ptosis & $4(7.01 \%)$ \\
\hline 7. Altered sensorium & $15(26.3 \%)$ \\
\hline 8. Nausea / Vomiting & $11(19.2 \%)$ \\
\hline 9. Fever & $5(8.7 \%)$ \\
\hline 10. Bleeding manifestations & $13(22.8 \%)$ \\
\hline Clinical signs & No. of Patients \\
\hline 1. Fever & $5(8.7 \%)$ \\
\hline 2. Tachycardia & $21(36.8 \%)$ \\
\hline 3. Respiratory distress & $14(24.5 \%)$ \\
\hline 4. Hypotension & $11(19.2 \%)$ \\
\hline 5. Edema & $19(33.3 \%)$ \\
\hline 6. Flapping Tremors & $9(15.7 \%)$ \\
\hline 7. Subconjunctival Bleeding & $5(8.7 \%)$ \\
\hline 8. Rash & $3(5.2 \%)$ \\
\hline 9. Pericardial Rub & $3(5.2 \%)$ \\
\hline 10. Crepitations & $12(21.05 \%)$ \\
\hline 11. Altered sensorium & $15(26.3 \%)$ \\
\hline 12. Extensor planters & $15(26.3 \%)$ \\
\hline
\end{tabular}

discharge (Group A )and death (Group B), and various parameters were compared between the two groups, which were Presence of Extensive cellulitis (i.e., cellulitis extending at least 2 joints above the site of bite), Coagulopathy (INR > 1.5), Uremic Encephalopathy, hyperkalemia (Serum Potassium $>5.5 \mathrm{mEq} / \mathrm{L}$ ), Mean Blood Urea, Mean serum creatinine, Mean Bite to needle time, Mean Dose of ASV, Mode of Dialysis ( i.e., Peritoneal Vs Haemodialysis).

SPSS for Windows version 17.0 (SPSS, Inc, Chicago,
Ill) was used for statistical analysis. The Pearson Chi-Square Test was used to analyze parametric variables. A P value of 0.05 or less was considered statistically significant.

\section{Results}

During the study period of 18 months a total of 532 patients were admitted for snake bite, of which 246 (46.24\%) patients 
Table 3. Patient Outcome as per Dialysis Mode

\begin{tabular}{lccc}
\hline & \multicolumn{2}{c}{ Outcome } & Total \\
\cline { 2 - 3 } Dialysis & Discharge & Death & \\
\hline HD & 13 & 1 & 14 \\
PD & 27 & 16 & 43 \\
Total & 40 & 17 & 57 \\
\hline
\end{tabular}

HD: Haemodialysis; PD: Peritoneal Dialysis

showed signs of envenomation, i.e., were due to a poisonous snake bite, 109 (20.48\%) patients developed acute renal failure. Among these 109 cases of ARF, 57 (52.29\%) patients required dialysis. Of these 57 patients, 17 (29.8\%) patients expired and $40(70.17 \%)$ patients survived. Thus overall mortality of snake bite induced ARF is $15.5 \%$. These 57 patients were studied in further details.

Of the 57 patients included in study, $48(84.2 \%)$ were males and $9(15.7 \%)$ were females. Mean age was $35.77( \pm$ $14.92)$ years. Rural patients were $49(85.9 \%)$ and urban patients were $8(14.03 \%)$.

The timing of snake bite, site of snake bite and the time lag between snake bite and administration of first dose of ASV are shown in Table 1.

The clinical characteristics of patients are shown in Table 2

On local examination, Fang Marks were seen in 22 $(38.5 \%)$ patients. Cellulitis was seen in all $57(100 \%)$ pa- tients, $4(7.01 \%)$ patients had skin necrosis, 1 patient had developed compartment syndrome, requiring fasciotomy.

Laboratory data showed anaemia $(\mathrm{Hb}<9$ gm \%) in 31 (54.3\%); leucocytosis in 35 (61.4\%); Thrombocytopenia in $24(42.1 \%)$; Coagulopathy in $21(36.8 \%)$; hematuria in 19 (33.3\%); albuminuria in 57 (100\%); metabolic Acidosis in $18(31.5 \%)$ and Hyperkalemia in $9(15.7 \%)$ patients. Mean Blood Urea was $148.40 \mathrm{mg} / \mathrm{dL}$, and mean serum creatinine was $6.60 \mathrm{mg} / \mathrm{dL}$. On radiological Investigations, 8 (14.02\%) patients had pulmonary edema in chest radiograph and on ultrasonography of Abdomen, 57 (100\%) patients had normal size kidneys, altered cortical echotexture and a normal cortico-medullary differentiation.

Out of these 57 patients, $43(75.43 \%)$ patients received peritoneal dialysis, and $13(22.8 \%)$ patients received hemodialysis. The patient outcome as per dialysis mode is shown in Table 3.

Thus the mortality was $7.14 \%$ with hemodialysis and

Table 4. Comparison Between Group A and Group B.

\begin{tabular}{llll}
\hline Parameter & $\begin{array}{l}\text { Group A } \\
\text { Discharge (n= 40) }\end{array}$ & $\begin{array}{l}\text { Group B } \\
\text { Death }(\mathbf{n}=\mathbf{1 7})\end{array}$ & P value \\
\hline $\begin{array}{l}\text { 1. Extensive cellulitis } \\
\text { 2. Coagulopathy }\end{array}$ & 14 & 9 & 0.621 \\
3. Uremic Encephalopathy & 5 & 13 & 0.004 \\
4. Hyperkalemia & 4 & 8 & 0.004 \\
5. Peritoneal Dialysis & 27 & 5 & 0.066 \\
6. Haemodialysis & 13 & 16 & 0.033 \\
\hline
\end{tabular}




\section{$37.20 \%$ with peritoneal dialysis.}

The comparison between Group A (Discharged patients) and Group B (Expired patients) is shown in Table 4, which shows significant $\mathrm{P}$ values for Coagulopathy, Uremic encephalopathy and peritoneal dialysis, indicating that these factors are associated with poor outcome.

\section{Discussion}

Snakebites have the highest incidence in Asia and represent an important health problem. Clinical renal manifestations include proteinuria, hematuria, pigmenturia, and renal failure. Nephropathy usually is caused by bites by snakes with hemotoxic or myotoxic venoms [9]. Acute renal failure is mainly observed following bites by the viperidae group, sea snakes and the colubridae group, but the substantial proportion of these cases result from viper bites. The incidence of acute renal failure (ARF) following poisonous snakes varies from 13 to 22\% following Echis carinatus or Russell's viper bite.

The exact pathogenesis of ARF following snake bite is not well established. However, a number of factors contribute, viz, bleeding, hypotension, circulatory collapse, intravascular hemolysis, disseminated intravascular coagulation, microangiopathic haemolytic anemia and direct nephrotoxicity of venom [10]. Tubular necrosis (53.6\%) and cortical necrosis $(24.3 \%)$ are the main causes of acute renal failure [7]. Acute interstitial nephritis has also been described [11].

Most of the patients were found to be men in working age group, especially from rural population. Majority of the snake bites occurred between 6 am to $10 \mathrm{pm}$, i.e., during working hours in the field. As expected, the snake bites more commonly involving lower limbs. So, this also shows that use of protective footwear can reduce the snake bites.

In our study, out of total number of snake bite patients, $20.48 \%$ patients developed acute renal failure. This prevalence is similar to the other studies from India [4, 12-22]; whereas the prevalence of acute renal failure in snake bite in studies from Nigeria, Israel, Thailand and Southeast Anatolia has been found to be $1-10 \%, 6.2 \%, 5 \%$ and $8 \%$ respectively [23-26]. The higher prevalence probably suggests delay in administration of ASV, as there is a delay in taking the patient to hospital after snake bite, which may be related to social factors, and the long distances that the tribal and rural people have to travel before reaching a health facility.

All of the patients had local cellulitis, indicating the vasculotoxic nature of envenomation. In viperine bites, the earliest symptom is development of pain and swelling due to cellulitis, which can spread over whole extremity, and can also lead to compartment syndrome threatening the viability of the limb or its part [27]. This can have important consequences if it leads to loss of digits due to ischemia and gangrene. The other common symptoms were oliguria $(84.2 \%)$, edema $(33.3 \%)$, which are consequences of renal failure in the patients, $29.8 \%$ had hematuria and other bleeding manifestations were present in $22.8 \%$ patients. Similar figures have been reported previously also [28].

Common findings on examination were tachycardia $(36.8 \%)$, respiratory distress $(24.5 \%)$, rales on chest auscultation (21.05\%), and hypotension (19.2\%). The hypotension can be result of various factors like bleeding, disseminated intravascular coagulation, vascular endothelial damage by the toxins which leads to plasma exudation. Early shock is probably explained by vasodilatation and late shock is precipitated by massive GI haemorrhage or acute pituitary and adrenal insufficiency [29]. Hypotension can be managed by early administration of ASV, timely correction of coagulopathy by administration of fresh frozen plasma or platelet concentrates as needed, and optimisation of intravascular volume by crystalloids.

Albuminuria was present in all $(100 \%)$ patients. This shows the toxin induced breakdown of the renal filtration barrier. However this finding is more useful in follow-up of these patients as persistent albuminuria can serve as a marker of residual renal dysfunction after recovery from acute renal failure [2]. Other common laboratory findings were Anaemia (54.3\%); Leucocytosis (61.4\%); Thrombocytopenia (42.1\%); Coagulopathy (36.8\%); Metabolic Acidosis $(31.5 \%)$. Coagulopathy is an important factor contributing to increased mortality. The prevalence of coagulopathy in this study $(36.8 \%)$ is comparable to that noted by Athappan et al [21] i.e., $27.7 \%$, whereas it is less as compared to other series $(60-80 \%)$ [13]. By itself, coagulopathy is a marker of the vasculotoxicity and hemotoxicity of the poison, which means that these patients will have nephrotoxicity due to damage to renal microvasculature. Also coagulopathy leads to bleeding and hypotension which, further leads to renal insufficiency as a result of prerenal insult.

The mortality of snake bite induced acute renal failure is found to be $15.5 \%$ in this study. This is less compared to estimates from other studies from India $(22-50 \%)[7,13,21]$. Kalantri et al reported an overall mortality of $11 \%$ in venomous snake bite patients [30]. The mortality can be prevented by intervention at various levels, which include early transfer of the patient to a primary health care facility, where ASV should be administered at the earliest. The high risk patients should be identified early and referred to higher canter. Patient's fluid status should be optimised, with early detection and treatment of coagulopathy. Further, renal replacement therapy should be initiated at the earliest to prevent serious consequences of uremia.

Furthermore, the comparison between the patients who survived and those who died showed a significant difference with regard to coagulopathy, uremic encephalopathy, and mode of dialysis, and no significant difference with regard to hyperkalemia and extensive cellulitis.

Though the comparison of hemodialysis and peritoneal 
dialysis in these patients showed that hemodialysis is associated with better results with regard to survival, this study is not designed to compare hemodialysis and peritoneal dialysis.

The limitations of this study were a smaller sample size, lack of investigations like renal biopsy, ELISA for D-dimer, ELISA for snake venom. Also, renal replacement modality, hemodialysis versus peritoneal dialysis were selected on basis of availability of resources, and patients were not matched with respect to confounding factors, so as to enable the study to compare the two modalities of renal replacement therapy.

This study concludes that acute renal failure occurs in $20.48 \%$ victims of snake bite. Common manifestations include cellulitis, oliguria, albuminuria, coagulopathy and thrombocytopenia. The overall mortality of snake bite induced acute renal failure is $15.5 \%$. Presence of coagulopathy and uremic encephalopathy are predictors of poor outcome in snake bite patients who develop acute renal failure. Though this study is not designed to compare hemodialysis and peritoneal dialysis, the better outcome in hemodialysis group suggests the need to compare the two modalities of renal replacement therapy in patients with snake bite induced acute renal failure.

\section{Grant Support}

NIL.

\section{Financial Disclosures}

NIL.

\section{References}

1. Kasturiratne A, Wickremasinghe AR, de Silva N, Gunawardena NK, Pathmeswaran A, Premaratna R, Savioli L, et al. The global burden of snakebite: a literature analysis and modelling based on regional estimates of envenoming and deaths. PLoS Med. 2008;5(11):e218.

2. Warrell DA. WHO/SEARO Guidelines for the clinical management of snakebite in the Southeast Asian Region. SE Asian J Trop Med Pub Hlth 1999;30:1-85.

3. Warrell DA. Injuries, envenoming, poisoning, and allergic reactions caused by animal. In: Warrell DA, Cox TN, Firth JD, Benz J Jr, editors. Oxford Textbook of Medicine. Oxford: Oxford University Press; 2003. p. 923-45.

4. Al-Homrany MA. Acute renal failure due to snakebite: clinical aspects. Saudi J Kidney Dis Transpl. 1998;9(3):285-289.

5. Simpson ID, Norris RL. Snakes of medical importance in India: is the concept of the "Big 4" still relevant and useful? Wilderness Environ Med. 2007;18(1):2-9.

6. Saini RK, Sharma S, Singh S, Pathania NS. Snake bite poisoning: a preliminary report. J Assoc Physicians India. 1984;32(2):195-197.

7. Mittal BV. Acute renal failure following poisonous snake bite. J Postgrad Med. 1994;40(3):123-126.

8. Mehta RL, Kellum JA, Shah SV, Molitoris BA, Ronco C, Warnock DG, Levin A. Acute Kidney Injury Network: report of an initiative to improve outcomes in acute kidney injury. Crit Care. 2007;11(2):R31.

9. Kanjanabuch T, Sitprija V. Snakebite nephrotoxicity in Asia. Semin Nephrol. 2008;28(4):363-372.

10. Kohli HS, Sakhuja V. Snake bites and acute renal failure. Saudi J Kidney Dis Transpl. 2003;14(2):165-176.

11. Sitprija V, Suvanpha R, Pochanugool C, Chusil S, Tungsanga K. Acute interstitial nephritis in snake bite. Am J Trop Med Hyg. 1982;31(2):408-410.

12. Chugh KS. Snake-bite-induced acute renal failure in India. Kidney Int. 1989;35(3):891-907.

13. Ali G, Kak M, Kumar M, Bali SK, Tak SI, Hassan G, Wadhwa MB. Acute renal failure following echis carinatus (saw-scaled viper) envenomation. Indian Journal of Nephrology 2004;14:177-181.

14. Bhat RN. Viperine snake bite poisoning in Jammu. J Indian Med Assoc. 1974;63(12):383-392.

15. Visweswaran RK, George J. Snake bite induced acute renal failure. Ind J Nephrol 1999; 9: 156-159.

16. Chugh KS, Pal Y, Chakravarty RN, Datta BN, Mehta $\mathrm{R}$, Sakhuja V, Mandal AK, et al. Acute renal failure following poisonous snakebite. Am J Kidney Dis. 1984;4(1):30-38.

17. Mittal BV, Kinare SG, Acharya VN. Renal lesions following viper bites--a study of 14 years. Indian J Med Res. 1986;83:642-651.

18. Chugh KS, Aikat BK, Sharma BK, Dash SC, Mathew MT, Das KC. Acute renal failure following snakebite. Am J Trop Med Hyg. 1975;24(4):692-697.

19. Shastry JC, Date A, Carman RH, Johny KV. Renal failure following snake bite. A clinicopathological study of nineteen patients. Am J Trop Med Hyg. 1977;26(5 Pt 1):1032-1038.

20. Basu J, Majumdar G, Dutta A, Sengupta SK, Kundu B, Dass S, Neelakantan C, et al. Acute renal failure following snake bite (viper). J Assoc Physicians India. 1977;25(12):883-890.

21. Athappan G, Balaji MV, Navaneethan U, Thirumalikolundusubramanian P. Acute renal failure in snake envenomation: a large prospective study. Saudi J Kidney Dis Transpl. 2008;19(3):404-410.

22. Sharma N, Chauhan S, Faruqi S, Bhat P, Varma S. Snake envenomation in a north Indian hospital. Emerg Med J. 2005;22(2):118-120.

23. Warrell DA, Davidson N, Greenwood BM, Ormerod 
LD, Pope HM, Watkins BJ, Prentice CR. Poisoning by bites of the saw-scaled or carpet viper (Echis carinatus) in Nigeria. Q J Med. 1977;46(181):33-62.

24. Efrati P, Reif L. Clinical and pathological observations of sixty-five cases of viper bite in Israel. Am J Trop Med Hyg. 1953;2(6):1085-1108.

25. Sitprija V, Boonpucknavig V. Snake venoms and nephrotoxicity, In : eds Lee CY. Berlin, Springer Verlag. Snake Venoms 1979: pp 1951-1953

26. Danis R, Ozmen S, Celen MK, Akin D, Ayaz C, Yazanel O. Snakebite-induced acute kidney injury: data from Southeast Anatolia. Ren Fail. 2008;30(1):51-55.

27. Ahmed SM, Ahmed M, Nadeem A, Mahajan J, Choudhary A, Pal J. Emergency treatment of a snake bite: Pearls from literature. J Emerg Trauma Shock. 2008;1(2):97105.

28. Mahmood K, Naqvi IH, Talib A, Salkeen S, Abbasi B, Akhter T, Iftikhar N, et al. Clinical course and outcome of snake envenomation at a hospital in Karachi. Singapore Med J. 2010;51(4):300-305.

29. Soe P, Russels Viper bite: Correlation of different clinical criteria to peritoneal dia $\neg$ lysis and clinical outcome, Regional Health Forum- Volume 9, Number 1, 2005.

30. Kalantri S, Singh A, Joshi R, Malamba S, Ho C, Ezoua J, Morgan M. Clinical predictors of in-hospital mortality in patients with snake bite: a retrospective study from a rural hospital in central India. Trop Med Int Health. 2006;11(1):22-30. 